\title{
Number of Lymph Nodes and MSI in Colon Cancer Surgery: Reply to Letter
}

\author{
Kjetil Søreide $\cdot$ Bjørn S. Nedrebø • Jon Arne Søreide • \\ Hartwig Kørner
}

Published online: 8 April 2010

(C) Société Internationale de Chirurgie 2010

We appreciate the interest in and comments on our recent article [1] by Dr. Hottenrott [2]. We agree that cancer in general, and colorectal cancer in particular $[3,4]$, is a highly complicated and heterogeneous disease for which it might be an oversimplification to believe that by measuring lymph nodes, or lymph node ratio (LNR), it would be possible to predict accurately oncologic outcomes in individual patients with colorectal cancers. Our study was not designed for, nor did it try to answer, what should be the best indicator, predictor, or prognosticator in colon cancer. In fact, we question the additional clinical value of LNR to the traditional TNM staging in our study [1]. Obviously, our understanding of quality indicators in colon surgery is in flux, and evidence is evolving with time $[5,6]$.

We recognize that our study was undertaken before laparoscopic colon cancer surgery was introduced and performed as a standard in our institution. As we state in the article [1], we believe that the standards achieved at the time (with only slightly more than one third having more than 12 nodes harvested) is reflective of that in the general literature on the subject at the same time period, and that the results should be viewed against these standards and not those of the current era. Consequently, replicating the results in other studies would be needed to confirm the validity and reliability of the findings.

Nonetheless, as we cannot improve surgical care for patients with colorectal cancer without understanding the

K. Søreide $(\bowtie) \cdot$ B. S. Nedreb $\varnothing$ J J. A. Søreide · H. Kørner Department of Surgery, Stavanger University Hospital,

Stavanger, Norway

e-mail: ksoreide@mac.com

\section{K. Søreide}

Department of Surgical Sciences, University of Bergen, Bergen, Norway tumor biology and how this may affect predictive and prognostic factors, we found it of utmost interest to investigate the effect of microsatellite instability (MSI) on the number of nodes harvested in this population [1]. The association of the right-sided colocation of MSI with higher numbers of lymph nodes is a novel finding in our study [1] and one that has not been reported previously to the best of our knowledge. When further elaborated in clinical series that include current standards of cancer surgery, the influence of tumor biology may further enlighten our understanding of quality indicators, predictors, and prognosticators in patients with colorectal cancer.

\section{References}

1. Søreide K, Nedrebø BS, Søreide JA et al (2009) Lymph node harvest in colon cancer: influence of microsatellite instability and proximal tumor location. World J Surg 33(12):2695-2703

2. Hottenrott C (2010) Moving from lymph nodes measurement to standardizing colon cancer surgery: letter to the editor. World $\mathrm{J}$ Surg 34. doi 10.1007/s00268-010-0488-2

3. Søreide K, Nedrebø BS, Knapp JC et al (2009) Evolving molecular classification by genomic and proteomic biomarkers in colorectal cancer: potential implications for the surgical oncologist. Surg Oncol 18(1):31-50

4. Søreide K, Janssen EA, Söiland H et al (2006) Microsatellite instability in colorectal cancer. Br J Surg 93(4):395-406

5. Hogan AM, Winter DC (2009) Complete mesocolic excision-a marker of surgical quality? J Gastrointest Surg 13(10):1889-1891

6. West NP, Morris EJ, Rotimi O et al (2008) Pathology grading of colon cancer surgical resection and its association with survival: a retrospective observational study. Lancet Oncol 9(9):857-865 